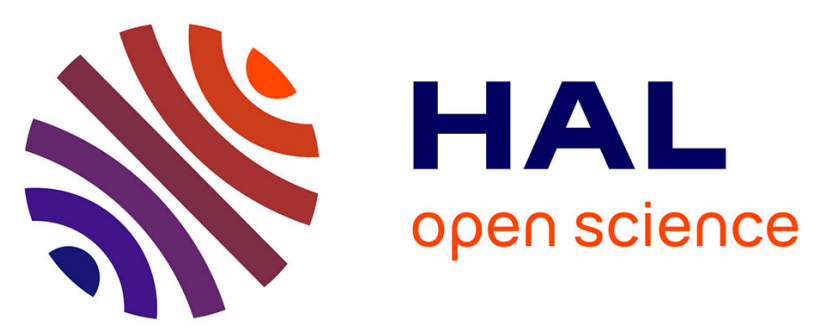

\title{
Prescription of drugs during pregnancy: a study using EFEMERIS, the new French database
}

\author{
I. Lacroix, C. Hurault, M. F. Sarramon, C. Guitard, A. Berrebi, M. Grau, C.
} Albouy-Cossard, R. Bourrel, E. Elefant, J. L. Montastruc, et al.

\section{- To cite this version:}

I. Lacroix, C. Hurault, M. F. Sarramon, C. Guitard, A. Berrebi, et al.. Prescription of drugs during pregnancy: a study using EFEMERIS, the new French database. European Journal of Clinical Pharmacology, 2009, 65 (8), pp.839-846. 10.1007/s00228-009-0647-2 . hal-00534955

\section{HAL Id: hal-00534955 https://hal.science/hal-00534955}

Submitted on 11 Nov 2010

HAL is a multi-disciplinary open access archive for the deposit and dissemination of scientific research documents, whether they are published or not. The documents may come from teaching and research institutions in France or abroad, or from public or private research centers.
L'archive ouverte pluridisciplinaire HAL, est destinée au dépôt et à la diffusion de documents scientifiques de niveau recherche, publiés ou non, émanant des établissements d'enseignement et de recherche français ou étrangers, des laboratoires publics ou privés. 


\title{
Prescription of drugs during pregnancy: a study using EFEMERIS, the new French database
}

\author{
I. Lacroix - C. Hurault • M. F. Sarramon • C. Guitard • \\ A. Berrebi • M. Grau • C. Albouy-Cossard - R. Bourrel • \\ E. Elefant • J. L. Montastruc • C. Damase-Michel
}

Received: 17 October 2008 /Accepted: 18 March 2009/Published online: 14 April 2009

(C) Springer-Verlag 2009

\begin{abstract}
Background Because of the limited data concerning drug risks in pregnancy, health professionals are often deprived of relevant and sufficient information related to prescribing or dispensing during pregnancy. However, previous studies have emphasised the widespread French prescription of several drugs (sometimes "typically French") which have not been assessed in pregnant women.

Objectives The aim of the present study was to create the first French database of drugs prescribed and dispensed during pregnancy and the outcome of these pregnancies.

Methods This feasibility study concerns pregnant women who gave birth to a baby between 1 July 2004 to 30 June 2005 in Haute-Garonne and who are registered in the French Health Insurance Service. Data sources include (1) the French Health Insurance Database (drugs prescribed
\end{abstract}

EFEMERIS (Evaluation chez la Femme Enceinte des MEdicaments et de leurs RISques)

\footnotetext{
I. Lacroix $(\bowtie) \cdot C$ C. Hurault • J. L. Montastruc · C. Damase-Michel Service de Pharmacologie Clinique, CHU de Toulouse,

Centre Midi-Pyrénées de Pharmacovigilance,

de Pharmacoépidémiologie et d'Information sur le Médicament,

Unité de Pharmacoépidémiologie, EA3696,

Université de Toulouse,

37 allées Jules Guesde,

31000 Toulouse, France

e-mail: lacroix@cict.fr

M. F. Sarramon

Centre de diagnostic anténatal, CHU de Toulouse,

Toulouse, France

C. Guitard · A. Berrebi

Service de Protection Maternelle et Infantile,

Conseil Général de la Haute-Garonne,

Toulouse, France
}

during pregnancy), (2) the Mother and Child Protection Centre Database (newborn health at birth and 9 months after) and (3) the Antenatal Diagnostic Centre Database (medical pregnancy interruptions).

Results The database is composed of 10,174 "motheroutcome" pairs. The prevalence rate of congenital anomalies was $2.2 \%$. Pregnant women were prescribed $11.3 \pm 8.2$ different drugs. Among the 20 most frequently prescribed drugs, around half of them have not been evaluated in pregnant women.

Conclusions The first results of this study show that implementation of a French database on prescription of drugs and pregnancy outcomes is feasible. Compared with several databases available in other countries, EFEMERIS provides exact data on period of exposure to drugs, pregnancy terminations, and follow up of the baby 9 months after birth. Recording these data would make it possible to assess the risk of malformations due

\section{Grau}

Caisse Primaire d'Assurance Maladie de la Haute-Garonne,

Toulouse, France

C. Albouy-Cossard

Centre d'Etudes des Sécurités du Système d'Information,

CNAMTS,

Paris, France

R. Bourrel

Caisse Régionale d'Assurance Maladie Midi-Pyrénées,

Toulouse, France

E. Elefant

Centre de Référence sur les Agents Tératogènes,

Paris, France 
to a greater number of drugs and would contribute to international drug evaluation studies.

Keywords Drug prescription · Pregnancy ·

Prescription database $\cdot$ Pharmacoepidemiology

\section{Introduction}

Evaluating the risks related to taking medication during pregnancy runs up against the difficulty of the almost complete lack (for ethical reasons) of clinical trials and the paucity of epidemiological data. Because of the limited data, physicians are often deprived of relevant and sufficient information regarding the prescription of medicines during pregnancy. However, studies carried out in France [1-6] reveal an elevated number of drugs (6 to 16 different drugs prescribed per woman according to the studies) during pregnancy. Certain drugs (e.g., misoprostol, non-steroidal anti-inflammatory drugs or converting-enzyme inhibitors during the last 3 months of pregnancy) known to be teratogenic, and for which the risk incurred exceeds the expected benefit, are often prescribed. These studies also show the widespread prescription of drugs which have not been evaluated during pregnancy, in particular drugs only marketed in France. Databases on drug prescriptions in pregnancy exist in some other European countries (e.g., Nordic countries, United Kingdom) linking prescription databases and birth registries.

The main aim of this study is to create the first French database of the drugs prescribed and dispensed during pregnancy and the outcome of these pregnancies (birth or medical termination of pregnancy). It concerns a feasibility study carried out in the Haute-Garonne Departement in the south-west of France.

\section{Methods}

The French Health Insurance System, Caisse Primaire d' Assurance Maladie (CPAM), refunds care and medications. For pregnant women, the first 3 months are reimbursed at 35 or $65 \%$ depending on the drug. Thereafter, care and medications are reimbursed at $100 \%$ until the end of pregnancy. All expecting mothers declare their pregnancy to the CPAM, which records the date of the beginning of pregnancy and of childbirth (sent by maternity services for reimbursement of hospital expenses). The Assurance Maladie systematically records all the drugs prescribed and dispensed to patients registered under general state coverage $(80 \%$ of the population) in order to refund the costs. Pharmacists who dispense medicines send the following data to the CPAM: the name of the person covered by health insurance, who the prescription is for, the refundable medicine, and the date it was dispensed. The collection of the data by the CPAM is prospective; there is no recall bias related to the occurrence or non-occurrence of any malformations.

All children have three compulsory medical examinations at 8 days, 9 months, and 2 years. The certificates filled out during these examinations are sent to the administrative services of the Mother and Child Protection Centre (Protection Maternelle et Infantile; PMI) by the physician who made out the certificate. Health certificates contain data concerning the mother (surname, first name and date of birth) and the child (weight, size, cranial circumference, APGAR score, neonatal diseases, congenital malformations, death and psychomotor development). Finally, the Antenatal Diagnostic Centre (Centre de diagnostic antenatal; CDA) centralizes all the occurrences of malformations in the maternities of the region where termination of pregnancy has been considered.

We have set up the EFEMERIS database (Evaluation chez la Femme Enceinte des MEdicaments et de leurs RISque) using data on prescription drugs dispensed to pregnant women and recorded by the CPAM of HauteGaronne and the outcomes of these pregnancies obtained from both the PMI and the CDA.

All pregnant women with general state coverage administrated by the CPAM of Haute-Garonne having given birth within a 1-year period from 1 July 2004 to 30 June 2005 were included in EFEMERIS. The women were informed of the study by post sent by CPAM and could refuse that information about them be recorded. We did not include women for whom data concerning their newborn were missing.

The data received from three sources (CPAM, PMI and CDA) were made anonymous before any transmission to the pharmacology service and before computer matching. The surname, first name and date of birth were all encrypted in the same way in the three databases generating the same irreversible code. In order to reduce the risk of different spellings of names in the three databases which could have led to loss of data, before anonymization we applied a program which removed spaces, accents and characters other than the letters $\mathrm{A}$ to $\mathrm{Z}$, turning double letters into a single letter, replacing $\mathrm{K}$ by $\mathrm{C}, \mathrm{W}$ by $\mathrm{V}$ etc. We then used a two-level anonymization architecture. The first level, configured via first-level secrecy, was carried out by the three information providers (CPAM, PMI and CDA) after selection and extraction of the data necessary to the study and before transmission to the pharmacology service. The second level, configured via second-level secrecy, was applied to the anonymous identifiers of the already encrypted first level by the pharmacology service before cross-referencing the three data sources. 
For this study, we obtained the authorization to process this personal information from the French government agency for the protection of personal data, the Commission Nationale de l'Informatique et des Libertés (CNIL).

\section{Results}

After anonymization, cross-referencing removed the information on children for whom we did not find any data concerning the mother and the files of mothers for whom the outcome of pregnancy had not been recorded (those for whom neither of the two certificates, 8 days or 9 months, were available). We were then left with a database of 10,008 pregnancies with 10,174 mother-outcome pairs (several multiple pregnancies) (Fig. 1). We checked that women excluded had comparable characteristics (e.g., age, prescribed drugs) as the included women (Table 1). We estimated that, according to the national statistics agency, INSEE [7], our sample accounts for $86 \%$ of the babies born in Haute-Garonne over the considered period.

Table 2 shows the general characteristics of the 10,144 newborns (weight, size, sex and APGAR at 1 and $5 \mathrm{~min}$ ). One can observe a prematurity rate of $6.1 \%$. Fifteen deaths $(1.5 \%)$ in the first days of life were reported. Two hundred newborns had a malformation, representing $2 \%$ of the population.

We found 30 cases of medical pregnancy interruption; $45 \%$ during the second trimester of pregnancy and 55\% during the third. The medical pregnancy interruptions were carried out on average at $28.4 \pm 4.6$ weeks of amenorrhoea (range 22 to 38 weeks). Twenty-nine medical pregnancy interruptions were justified by the presence of malformations. In one case, the medical pregnancy interruption was undertaken because of anamnios following amniotic sac rupture. Malformations having justified pregnancy interruption most frequently affected the central nervous system (33\% of the cases), the cardiovascular system $(27 \%)$, the urinary tract $(20 \%)$, and the musculoskeletal system $(20 \%)$ (Table 3). In $23 \%$ of pregnancy interruptions, intrauterine growth retardation was observed. In $20 \%$ of the cases, a genetic abnormality was detected.

Altogether (for newborns and medical pregnancy interruptions), we observed a malformation rate of $2.2 \%: 228$ newborns or foetuses (medical pregnancy interruptions) had at least one malformation. Osteomuscular, urinary, cardiovascular, and nervous system malformations were most frequent (Table 4).

The average age of the women was $30.2 \pm 5.0$ years and ranged from 15 to 47 years. The average length of pregnancy was $37.6 \pm 1.7$ weeks.

Ninety-five percent of the women had at least one drug prescribed during their pregnancy $(93 \%$ when iron and vitamins were excluded). The number of different drugs prescribed during pregnancy ranged from 0 to 76 with an average of $11 \pm 8$. We sorted the drugs prescribed according to the ATC classification. The pregnant women had most commonly taken drugs from the "alimentary tract and metabolism" (80\%), "nervous system" $(67 \%)$, "respiratory system" (58\%) and "blood and blood-forming organs" (56\%) classes (Table 5).

In the "alimentary tract and metabolism" class, the most prescribed drugs were antiemetics [metoclopramide $(20 \%$ of newborns exposed) and domperidone (17\%)], and antiacids and antispasmodics [phloroglucinol (37\%)]. In the "nervous system" class, $65 \%$ of the newborns were exposed to analgesics, primarily paracetamol $(63 \%)$. About $1 \%$ of women had at least one neuroleptic during their
Fig. 1 Number of mother-outcome pairs




Table 1 General characteristics of included and excluded women

\begin{tabular}{lll}
\hline & $\begin{array}{l}\text { Included } \\
\text { (mean or \%) }\end{array}$ & $\begin{array}{l}\text { Excluded } \\
\text { (mean or \%) }\end{array}$ \\
\hline $\begin{array}{l}\text { Age of mothers (years) } \\
\text { Prescriptions (number of specialties) }\end{array}$ & 30 & 30 \\
Newborns & 9 & 9 \\
Weight $(\mathrm{g})$ & 3,264 & 3,263 \\
Length $(\mathrm{cm})$ & 49 & 49 \\
Sex male & $52 \%$ & $51 \%$ \\
Malformation rate & $2 \%$ & $2 \%$ \\
\hline
\end{tabular}

pregnancy, $2 \%$ antidepressants, $3 \%$ benzodiazepine, and $1 \%$ another hypnotic or anxiolytic. Bromazepam was the most prescribed benzodiazepine. In the "respiratory system" class, cold and cough drugs were the most prescribed (37\% of newborns exposed) with many prescriptions for helicidine (22\%), fusafungine (16\%), chlorhexidine (16\%) and tuaminoheptane (15\%). In the "blood and bloodforming organs" class, there were mainly prescriptions for iron, which was the second most commonly prescribed drug for pregnant women, with $52 \%$ having taken them.

Table 6 presents the most often prescribed active ingredients. Among the 20 most prescribed active ingredients, there were well evaluated drugs such as paracetamol and amoxicillin but also many insufficiently evaluated drugs such as phloroglucinol, helicidine, hesperidin, diosmine, domperidone, fusafungine, sodium alginate, chlorhexidine, bacitracin and tuaminoheptane.

\section{Discussion}

We have described the implementation of EFEMERIS, the first French database on the prescription of drugs to pregnant women. This feasibility study, the first of its kind in France, has made it possible to study 10,174 mother-outcome pairs. Our sample of newborns represents nearly $86 \%$ of the children born in Haute-Garonne over the period studied [7]. Databases on drug prescriptions during pregnancy have already been implemented and used in many countries (e.g., the United Kingdom, Finland, Denmark, Sweden, the Netherlands and Norway) [8-13]. They are used for drug safety alerts on malformations. They also allow the evaluation of physicians' prescription practices. This kind of monitoring system should exist in every country because of the differences in the drugs available to prescribing physicians and national prescription characteristics.

There are malformation registers in France. Their objectives and methods (retrospective case-control studies) differ and complement the studies carried out using
Table 2 General characteristics of the 10,144 newborns

\begin{tabular}{|c|c|}
\hline Characteristic & Value \\
\hline Prematurity & $615(6.1 \%)$ \\
\hline Neonatal death & $15(1.5 \%)$ \\
\hline \multicolumn{2}{|c|}{ At birth $\left(9,902\right.$ 8-day certificates $\left.{ }^{\mathrm{a}}\right)$} \\
\hline Weight(g) & $3,264( \pm 512)$ \\
\hline Length (cm) & $49( \pm 2.4)$ \\
\hline Head circumference $(\mathrm{cm})$ & $34( \pm 1.7)$ \\
\hline \multicolumn{2}{|l|}{ Sex } \\
\hline Male & $5,079(51.3 \%)$ \\
\hline Female & $4,771(48.2 \%)$ \\
\hline NA & 52 \\
\hline \multicolumn{2}{|l|}{ APGAR $1 \mathrm{~min}$} \\
\hline$\leq 4$ & $72(0.7 \%)$ \\
\hline $5-7$ & $185(1.9 \%)$ \\
\hline $8-9$ & $393(4 \%)$ \\
\hline 10 & $7,223(72.9 \%)$ \\
\hline NA & 2,029 \\
\hline \multicolumn{2}{|l|}{ APGAR $5 \mathrm{~min}$} \\
\hline$\leq 4$ & $19(0.2 \%)$ \\
\hline $5-7$ & $28(0.3 \%)$ \\
\hline $8-9$ & $154(1.6 \%)$ \\
\hline 10 & $8,954(90.4 \%)$ \\
\hline NA & 747 \\
\hline \multicolumn{2}{|c|}{ At 9 months $\left(7,867\right.$ 9-month certificates $\left.{ }^{\mathrm{a}}\right)$} \\
\hline Weight (g) & $8,849( \pm 1,032)$ \\
\hline Length (cm) & $72( \pm 2.8)$ \\
\hline Head circumference $(\mathrm{cm})$ & $45( \pm 1.7)$ \\
\hline \multicolumn{2}{|l|}{ Psychomotor capacity } \\
\hline Can sit & $7,508(95.4 \%)$ \\
\hline NA & 196 \\
\hline Reacts to his/her name & $7,602(96.6 \%)$ \\
\hline NA & 199 \\
\hline Repeats syllables & $7,428(94.4 \%)$ \\
\hline NA & 205 \\
\hline Can move & $6,060(77 \%)$ \\
\hline NA & 213 \\
\hline
\end{tabular}

Values are number $(\%)$ or mean $( \pm \mathrm{SD})$. $N A$ Not available

${ }^{a}$ For several babies, only one of the two certificates was available

prescription databases. There are also databases in information centres (Centre de Référence sur les Agents Tératogènes and Centres Régionaux de Pharmacovigilance). These consist of recorded questions asked by health professionals about "drugs and pregnancy" and the outcomes of the pregnancies. Their objectives and methods differ and complement the studies carried out using prescription databases. Compared with several other prescription databases related to pregnancy, EFEMERIS has several advantages: it will elicit information to 
Table 3 Malformations having justified pregnancy interruption $(n=29$ foetuses)

\begin{tabular}{lll}
\hline Malformations & Number $^{\mathrm{a}}$ & Percentage of foetuses (\%) \\
\hline Nervous system & 10 & 33 \\
Cardiovascular system & 8 & 27 \\
Chromosomal & 6 & 20 \\
$\quad$ abnormalities & & 20 \\
Urinary system & 6 & 20 \\
Musculoskeletal system & 6 & 13 \\
Eye, ear, face and neck & 4 & 10 \\
Digestive system & 3 & 3 \\
Respiratory system & 1 & \\
\hline
\end{tabular}

${ }^{\mathrm{a}}$ One foetus can be affected by several malformations

evaluate drug risk in pregnancy since pregnancy outcomes are available and will provide information on children up to the age of 2 years ( 9 months for the feasibility study). EFEMERIS contains real dates for the beginning of pregnancy, i.e., the exact period of drug exposure is known. It also contains data concerning therapeutic terminations which can be due to a teratogenic drug.

Among the limitations of the EFEMERIS database, it should be pointed out that the CPAM does not record drugs taken during hospitalization, drugs only dispensed at hospital or drugs which are not reimbursed. We do not have data on self-medication. There is therefore the possibility of underestimating the number of drugs taken by the women in our study. Conversely, there might be an overestimating factor since we cannot be sure that the patients included in the study really took the prescribed drugs. However, our study concerns drugs prescribed but also dispensed by the pharmacist. Under the method used,

Table 4 Most frequent malformations

\begin{tabular}{lll}
\hline Malformations & Number & Per mille (\%) \\
\hline Musculoskeletal system & 58 & 5.7 \\
Urinary system & 55 & 5.4 \\
Cardiovascular system & 45 & 4.4 \\
Nervous system & 25 & 2.5 \\
$\quad$ Spina bifida & 2 & \\
Genital organ & 22 & 2.2 \\
Chromosomal abnormalities & 20 & 2.0 \\
$\quad$ Trisomy 21 & 4 & \\
Digestive system & 15 & 1.5 \\
Cleft lip and palate & 8 & 0.8 \\
Eye, ear, face and neck & 7 & 0.7 \\
Respiratory system & 2 & 0.2 \\
Other & 2 & 0.2 \\
\hline
\end{tabular}

we also could not include women who had a spontaneous miscarriage. These biases are also present in the other European studies of prescription drugs. Moreover, we have checked that excluded women have the same characteristics as the included ones.

Data concerning neonates (weight, size and prematurity rate) in our study are comparable with those of the French general population, according to the results of the National Perinatal Investigation in 2003 including 15,378 births in France as a whole [14]. The $2.2 \%$ malformation rate and the distribution of the various types of malformations are also consistent with the data in the literature [15-17]. The medical pregnancy interruption rate is similar to that reported in the National Perinatal Investigation ( 0.3 versus $0.4 \%$ ).

This study demonstrates that drugs are widely prescribed to pregnant women, which tallies with the study we carried out 10 years ago [6]. The rate of pregnant women having received at least one drug prescription is as high as in many other studies carried out in the United States, Germany or Norway $[13,18,19]$. In other countries such as Finland, Italy, the Netherlands and the United Kingdom [8, 12, 20$22]$, the rate is slightly lower $[63,(70,75), 79$ and $65 \%$, respectively). The average number of different active ingredients prescribed per woman is still higher in France compared with the other countries (11.3 versus 1.2 to 7 ). Nguyen et al. have shown that the prescription status or the level of refunding does not account for the differences in drug consumptions observed among countries such as England, Germany and France [23].

The most prescribed classes of drugs differ considerably from country to country. In several studies, anti-infectives were the drugs most prescribed during pregnancy $[8,13$, 19, 21]. "Alimentary tract and metabolism" class drugs, which are at the top in our study, were prescribed far less frequently in other countries $(80 \%$ versus 4 to $10 \%$ depending on the study). This difference undoubtedly arises from the mass use of phloroglucinol in France $37 \%$ of the women). In the "nervous system" class, $6 \%$ of women are exposed to psychotropic drugs (anxiolytics, antidepressants or antipsychotics). This rate is rather high compared with what is observed in other countries: in Finland, a study on nearly 8,000 women [24] resulted in a rate of $1.5 \%$, and Marchetti et al. [25] studying 15,000 women in 22 countries found $3.5 \%$. Compared to the latter study, the rates of women exposed to various psychotropics were similar (neuroleptics and benzodiazepines) except for antidepressants with 20 times more women having taken them in our study. Concerning benzodiazepines, oxazepam, with its favourable pharmacokinetic profile (intermediate half life and no active metabolites) only comes in the sixth position of the benzodiazepines most prescribed during pregnancy. The most prescribed benzodiazepines during the 
Table 5 Most often prescribed ATC classes

\begin{tabular}{llll}
\hline & ATC classes & Exposed newborns $(n)$ & Exposed newborns (\%) \\
\hline A & Alimentary tract and metabolism & 8,085 & 80 \\
N & Nervous system & 6,771 & 67 \\
R & Respiratory system & 5,867 & 58 \\
B & Blood and blood-forming organs & 5,695 & 56 \\
D & Dermatologicals & 4,276 & 42 \\
J & Anti-infectives & 4,228 & 42 \\
C & Cardiovascular system & 3,573 & 35 \\
G & Genitourinary system and sex & 3,503 & 34 \\
M & Musculoskeletal system & 1,805 & 18 \\
H & Systemic hormonal preparations & 1,476 & 15 \\
S & Sensory organs & 1,038 & 10 \\
& Homeopathic & 665 & 7 \\
V & Various & 502 & 5 \\
P & Antiparasitic products & 271 & 3 \\
Z & Others & 62 & 0.6 \\
L & Antineoplastic and immunomodulating agents & 16 & 0.2 \\
\hline
\end{tabular}

third trimester of pregnancy, bromazepam, diazepam and prazepam, are long half-life drugs $(2-150 \mathrm{~h})$. Studies showed that floppy infant syndrome and neonatal withdrawal syndrome were less frequent or shorter and less severe when shorter half-life benzodiazepines such as oxazepam were used. As in the Dutch [12] and German

Table 6 Most often prescribed drugs

\begin{tabular}{ll}
\hline Drugs & Percentage of newborns exposed (\%) \\
\hline Paracetamol & 63 \\
Iron & 52 \\
Folic acid & 44 \\
Phloroglucinol & 37 \\
Magnesium & 31 \\
Amoxicillin & 26 \\
Econazole & 24 \\
Helicidine & 22 \\
Hesperidin & 20 \\
Metoclopramide & 20 \\
Diosmin & 20 \\
Pyridoxine & 18 \\
Domperidone & 17 \\
Fusafungine & 16 \\
Sodium alginate & 16 \\
Chlorhexidine & 16 \\
Bacitracin & 15 \\
Tuaminoheptane & 15 \\
Cholecalciférol & 14 \\
Salbutamol & 11 \\
\hline
\end{tabular}

[19] studies, a major reduction in the prescription of psychotropic drugs towards the end of pregnancy, in particular of neuroleptics and antidepressants, was seen (one-sixth as many women were exposed). The cause of this is worth looking into. Wasn't the drug needed? Or was it the fear of some neonatal condition that led to the drug being stopped? If so, there is a risk of aggravating the patient's pathology.

Among the 20 most prescribed drugs, half were drugs which have not been evaluated during pregnancy. Some of them, such as phloroglucinol (antispasmodic), helicidine (mucoglycoprotein extracted from snail mucus used as cough suppressant), tuaminoheptane (sympathomimetic used as nasal decongestant) and veinotonics, are only marketed in some European countries. Others are marketed in many countries, in particular in English-speaking ones but they have not been subjected to follow-ups in pregnant women, perhaps because they are less often prescribed than in France. This is true for domperidone, which is widely prescribed in France to pregnant women to treat nausea, vomiting and gastro-oesophageal reflux, whereas no data have been published on its prescription to humans. Thus, the EFEMERIS database will elicit information to evaluate these drugs which are less frequently taken in other countries.

Among the drugs for which human data are available, some with proven teratogenic or foetotoxic effects (the risks being higher than the potential benefit obtained) were prescribed and dispensed to patients included in the EFEMERIS database. This is true, for example, for retinoids which are highly teratogenic drugs, with 20 newborns exposed in utero including 16 during the first 
trimester. Non-steroidal anti-inflammatory drugs (NSAIDs) are formally contraindicated after the beginning of the sixth month of pregnancy because of their foetal and/or neonatal cardiac toxicity (premature closure of the ductus arteriosus) and/or renal toxicity which is sometimes fatal. Nevertheless, in the third trimester of pregnancy, 337 women received at least one prescription and dispensing for NSAID. The number of women exposed to these drugs and currently included in EFEMERIS is insufficient to analyze the outcomes of these pregnancies.

\section{Conclusions}

The first results of this study show that implementation of a French database on prescription of drugs and pregnancy outcomes is perfectly feasible. Compared with several databases available in other countries, it provides data on period of exposure to drugs, pregnancy terminations, and follow-up of the babies 9 months after birth.

Recording these data would make it possible to assess the risk of malformations due to a greater number of drugs or, on the contrary, to demonstrate the innocuousness of others. This database would constitute a monitoring centre for the prescription of drugs to pregnant women and would allow the impact of measures implemented by health authorities to be evaluated. Topics requiring additional dissemination on the risks of particular drugs during pregnancy to health professionals could be highlighted. Finally, it would also enable drugs which are less prescribed in other countries to be evaluated and enable participation in European or international pharmacoepidemiological studies to evaluate drugs prescribed to pregnant women.

Acknowledgements Financial support: Agence Française de Sécurité SAnitaire des Produits de Santé (AFSSAPS), Caisse Nationale d'Assurance Maladie des travailleurs salariés (CNAMTS), Mutuelle Générale de l'Education Nationale (MGEN), Unions régionales des Caisses d'Assurance Maladie (URCAM).

\section{References}

1. Barriere N, Meunier P, Chante F, Grassin J (1992) Enquête sur la prise de médicaments pendant la grossesse. Pharm Hosp Fr 100:1791-1794

2. Berthier $\mathrm{M}$, Bonneau $\mathrm{D}$, Perault $\mathrm{MC}$, Oriot $\mathrm{D}$, Chabot $\mathrm{F}$, Maillauchaud MC, Magnin G, Vandel B (1993) Medications exposure during pregnancy. Thérapie 48:43-46

3. Gobet JC, Petit G, Rotivel Y, Loupi E, Descotes J, Lery N (1980) Consommation médicamenteuse de la femme enceinte: à propos d'une enquête rétrospective chez 1000 femmes ayant accouché dans les maternités lyonnaises. Lyon Med 20:403409

4. Jonville AP, Lionnet C, Swar A, Dutertre JP, Barbier P, Autret E, Ch B (1991) Consommation médicamenteuse en fin de grossesse. Thérapie 46:379-382

5. Spreux A, Chichmanian RM, Jean-Girard C, Nouchi J (1991) Enquête prospective OMEGA. Thérapie 46:369-372

6. Lacroix I, Damase-Michel C, Lapeyre-Mestre M, Montastruc JL (2000) Prescription of drugs during pregnancy in France. Lancet $356: 1735-1736$

7. INSEE (2009) http://www.insee.fr/fr/themes/tableau.asp?reg id $=99 \&$ ref id $=$ CMRnon 02225

8. Hardy JR, Leaderer BP, Holford TR, Hall GC, Bracken MB (2006) Safety of medications prescribed before and during early pregnancy in a cohort of 81975 mothers from the UK General Practice Research Database. Pharmacoepidemiol Drug Saf 15:555-564

9. Hemminki E, Gissler M (1993) Quantity and targeting of antenatal care in Finland. Acta Obstet Gynecol Scand 72:24-30

10. Hjollund NH (1996) Information on previous spontaneous abortions in the Medical Birth Registry. Ugeskr Laeger 158:4746-4748

11. Gunnarskog J, Bengt Källen AJ (1993) Drug intoxication during pregnancy: a study with central registries. Reprod Toxicol 2:117-121

12. Bakker MK, Jentink J, Vroom F, Van Den Berg PB, De Walle HE, De Jong-Van Den Berg LT (2006) Drug prescription patterns before, during and after pregnancy for chronic, occasional and pregnancy-related drugs in the Netherlands. BJOG 113:559-568

13. Engeland A, Bramness JG, Daltveit AK, Ronning M, Skurtveit S, Furu K (2008) Prescription drug use among fathers and mothers before and during pregnancy. A population-based cohort study of 106000 pregnancies in Norway 2004-2006. Br J Clin Pharmacol 65:653-660

14. Blondele B, Supernant K, du Mazaubrun C, Breart G (2003)Enquete nationale perinatale. http://www.sante.gouv.fr/htm/dossiers/ perinat03/enquete.pdf. Unité de Recherches Epidémiologiques en Santé Périnatale et Santé des Femmes, Villejuif

15. De Vigan C, Khoshnood B, Lhomme A, Vodovar V, Goujard J, Goffinet F (2005) Prévalence et diagnostic prénatal des malformations en population parisienne: vingt ans de surveillance par le Registre des malformations congénitales de Paris. J Gynécol Obstét Biol Reprod 34(1):8-16

16. Rankin J, Pattenden J, Abramsky L, Boyd P, Jordan H, Stone D, Vrijheid M, Wellesley D, Dolk H (2005) Prevalence of congenital anomalies in five British regions, 1991-99. Arch Dis Child Fetal Neonatal Ed 90:F374-379

17. Dastgiri S, Stone DH, Le-Ha C, Gilmour WH (2002) Prevalence and secular trend of congenital anomalies in Glasgow, UK. Arch Dis Child 86:257-263

18. Andrade SE, Gurwitz JH, Davis RL, Chan KA, Finkelstein JA, Fortman K, McPhillips H, Raebel MA, Roblin D, Smith DH, Yood MU, Morse AN, Platt R (2004) Prescription drug use in pregnancy. Am J Obstet Gynecol 191:398-407

19. Egen-Lappe V, Hasford J (2004) Drug prescription in pregnancy: analysis of a large statutory sickness fund population. Eur J Clin Pharmacol 60:659-666

20. Malm H, Martikainen J, Klaukka T, Neuvonen PJ, Finnish Register-Based Study (2003) Prescription drugs during pregnancy and lactation-a Finnish register-based study. Eur J Clin Pharmacol 59:127-133

21. Donati S, Baglio G, Spinelli A, Grandolfo ME (2000) Drug use in pregnancy among Italian women. Eur J Clin Pharmacol 56:323-328 
22. Gagne JJ, Maio V, Berghella V, Louis DZ, Gonnella JS (2008) Prescription drug use during pregnancy: a population-based study in Regione Emilia-Romagna, Italy. Eur J Clin Pharmacol 64:1125-1132

23. Nguyen-Kim L, Or Z, Paris V, Sermet C (2005) Les politiques de prise en charge des médicaments en Allemagne, Angleterre et France. Bull d'Inf Econ Santé 99:1-6
24. Larivaara P, Hartikainen AL, Rantakallio P (1996) Use of psychotropic drugs and pregnancy outcome. J Clin Epidemiol 49:1309-1313

25. Marchetti F, Romero M, Bonati M, Tognoni G (1993) Use of psychotropic drugs during pregnancy. A report of the international co-operative drug use in pregnancy (DUP) study. Collaborative Group on Drug Use in Pregnancy (CGDUP). Eur J Clin Pharmacol 45:495-501 